\author{
Л.О. Чернейко \\ Московский государственный университет им. М. В. Ломоносова \\ (Россия, Москва) \\ avollis@mail.ru
}

\title{
МЕТОНИМИЯ МЕТАФОРЕ: ПАРАДОКС КОГНИТИВНОЙ МЕТАФОРЫ
}

В статье рассматривается ряд теоретических вопросов, связанных как с эпидигматикой (в частности, с типологией производного значения слова), так и с типологизацией когнитивной метафоры. Акцент делается на таком употреблении уже существующих лексических единиц, которые Аристотель назвал «переносными» именами и которые являются одним из важнейших предметов неологии. Важным при этом представляется герменевтический аспект изучения переносных метафорических употреблений слова в художественном тексте, ставящий целью раскрыть их мотивационную базу. Когнитивная метафора, осложненная метонимией, лежащей в ее основе, представляет собой наиболее трудный для понимания троп и относится по своей структуре к метафоре-загадке. На материале поэтических текстов предлагается интерпретация неочевидных для понимания «переносов» (Галчонком глянет Рождество - Б. Пастернак). Особое внимание уделяется абстрактным субстантивам, для которых когнитивная метафора представляет собой естественную форму речевого существования, связанного с вербализацией невидимого мира и создающего его признаковую лексику. Трактовка Р. Якобсоном метафоры как «параллелизма, эллиптически сведенного к точке», относится не ко всякой метафоре, а только к когнитивной, осложненной метонимией — к «метонимической метафоре». В статье предложено понимание механизма метафоризации метонимии: целое называется по своей части, но частью является не предмет одежды, а гипостазированный параметр, обрастающий своими вторичными предикатами, что продемонстрировано на примерах из художественных текстов и на сравнении переводов «Сонета 66» Шекспира.

Ключевые слова: Косвенно-производное значение, загадка, метаморфоза, метафора, метонимия, метонимическая метафора, ассоциативный смысл.

1.1. Не будет преувеличением сказать, что из всех тропов метафора является и самым древним лингвофилософским объектом, и самым изученным. Однако не выработан единый свод лингвистических параметров, по которым можно было бы 
охарактеризовать все известные науке типы и подтипы метафоры, а также описать некоторые словоупотребления, не вписывающиеся в существующую типологию.

Давая именам фукнционально-грамматические характеристики в «Поэтике», Аристотель ввел разные параметры, из которых наиболее важной для характеристики слов представляется оппозиция «общеупотребительное/редкое», поскольку в категорию «редкие» (Аристотель еще называет их именами «необычными») попадают и «не-свои» имена (заимствованные), и измененные как в словообразовательном аспекте (имена «удлиненные» и «укороченные»), так и в аспекте эпидигматическом (имена «переносные»), а также имена «сочиненные» (собственно неологизмы) [Аристотель 1978].

Достоинство речи Аристотель видел в том, чтобы она была «ясной» и не была «низкой» [Там же: 149], а «самая ясная речь та, которая состоит из общеупотребительных слов» при одном недостатке - она «низка». Речь же торжественная, состоящая из таких «необычных» (не общеупотребительных) слов, как имена «переносные», представляет собой загадку, поскольку далеко не всегда и не всем очевиден мотив переноса (иными словами, внутренняя форма «переносного» имени). Как метаязыковую энигму можно квалифицировать понятие «переносное значение» слова, поскольку под него подводятся все производные значения знаменательных слов без учета той функции, которую выполняет перенос предметного имени с одного класса явлений на другой.

1.2. Положив в основу разграничения типов лексических значений слова функциональный подход, В.В. Виноградов ввел для имени существительного понятия «номинативно-производное» и «косвенно-производное» типы значения [Виноградов 1977]. Номинативно-производные значения существительного восполняют лакуны лексикона, сохраняя образность, обусловленную очевидностью мотивации (капли как 'лекарственная форма', спутник — 'летательный аппарат').

Косвенно-производное значение имени, служа целям характеризации, оценки уже названного явления, обретает статус предиката и занимает соответствующее предикату место в высказывании: как правило, это именная часть сказуемого в предложениях метафорического тождества (Жизнь моя - кинематограф, чернобелое кино. Ю. Левитанский) либо так называемая «скрытая» предикация в структуре генитивной метафоры (И в полумраке затонуло воды игривое стекло. А. Фет), создающие возможность одновременного видения двух явлений, т.е. образ в том лингвистическом понимании термина «образ», которое представлено в концепциях Н. Д. Арутюновой, М. Блэка, В.Н. Телия и которое предполагает его двуплановость, проистекающую из совмещения двух представлений об одном явлении, сложно взаимодействующих и «переплавляющихся» в единое фигуральное, тропеическое обозначение референта. Именно косвенно-производное значение следует считать собственно переносным, фигуральным в отличие от номинативно-производного, не утратившего в своем содержании мотивационной основы, выполняющей в производном слове-омониме роль внутренней формы, и именно этот результат внутрисловной (семантической) деривации создает «Т-язык-tensive language» (по Ф. Уилрайту [Уилрайт 1990]), «коннотативную систему» (по Р. Барту [Барт 1975]). 
1.3. Сущность загадки Аристотель определяет как «соединение невозможного» в отображении действительного ${ }^{1}$. С загадкой связывал отображение действительности в языке и Г. Г. Шпет ${ }^{2}$, а в типологии метафор, предложенной Ю. И. Левиным, метафора-загадка выделена в особый структурный класс метафор [Левин 1998], коррелирующих с метафорой когнитивной (в предложенной Н.Д. Арутюновой классификации). Однако в любых, даже самых слабых «деформациях» семантических отношений, которые привлекают внимание читателя (слушателя) к знаку как таковому, обнаруживает себя не только эстетическая, поэтическая функция языка, но и интеллектуальная: загадку разгадать иногда непросто.

Интеллектуально-эстетическая ценность метафоры состоит для Аристотеля в ее краткости, т.е. в способности минимальными языковыми средствами передать новые смыслы и представления. В. Шкловский писал, что «мыслящие машины прозаичны и лежат вне искусства, потому что протаптывают короткие пути» [Шкловский 1974: 478]. Короткий путь нужен логике. Но и метафора «протаптывает короткие пути» к чувству и воображению человека. Однако метафора, «короткая» для говорящего ${ }^{3}$, может стать достаточно длинной для слушающего, имеющего дело с загадкой. А ценность переноса имени, создающего метафору, состоит не только в сближении говорящим «далековатых» понятий, но и в мотивационной основе сближения, делающего его понятным.

2.1. Связывая поэтическое наименование с эстетической функцией языка и выделяя в качестве главной особенности поэтического наименования его включенность в контекст, способствующий созданию нетривиальных («неавтоматизированных») образов, Я. Мукаржовский считает, что «ослабление непосредственного отношения к реальности делает из наименования поэтический прием» [Мукаржовский 1994: 134]. Конечно, для слова в поэтическом тексте не столь важна его связь с внеязыковой действительностью (с референтом), сколь важна она для обыденной коммуникации, однако без этой связи теряется загадка «переносного» имени, или имени в переносном значении. Основную задачу поэтики О. Мандельштама Ю. И. Левин видел в создании им «новых смыслов», «уникальных, доселе не существовавших семантических комплексов, не укладывающихся в рамки “здравого смысла”», но обусловленных, мотивированных явлениями реального мира, с которыми эти смыслы, несмотря на их «сублимированность» (определение Ю. Левина), «находятся в определенных отношениях» [Левин 1998: 51].

1 «В загадке сущность состоит в том, чтобы говорить о действительном, соединяя невозможное, - сочетанием общеупотребительных слов этого сделать нельзя, сочетанием же переносных можно» [Аристотель 1978: 149].

${ }^{2}$ Говоря об осмысленной (т. е. семиотизированной) человеком действительности, Г.Г. Шпет писал: «Действительность как она расстилается перед нами..." “дана” как вопрос и загадка» [Шпет 1991: 231].

3 Психотерапевт В. Леви, говоря о некоторых продуктах питания, называет их «ядами» и комментирует выбор метафорического обозначения: «“Яды” — это, конечно, некоторая гипербола, просто так покороче сказать» (В. Леви. Разговор в письмах). 
2.2. В хорошо известном раннем стихотворении Б. Пастернака «Про эти стихи», написанном летом 1917 г., есть такая строка: Галчонком глянет Рождество, вписанная в контекст: Внезапно вспомню: солнце есть; Увижу: свет давно не тот. Галчонком глянет Рождество, И разгулявшийся денек Прояснит много из того, Что мне и милой невдомек. Приглагольный творительный сравнения вводит объект сравнения, а субъектом выступает имя Рождество. Перед нами метаморфоза, как будто бы самая простая для дешифровки тропеическая конструкция. Эта метаморфоза легко превращается в сравнительный оборот: Рождество глянет, как галчонок. Но почему галчонок и КАК глядит галчонок, в чем особенность его взгляда?

Небольшой эксперимент со студентами филфака МГУ, которым был задан этот вопрос (всего 20 человек), позволил при обобщении проанализированных интерпретаций выделить повторяющиеся смыслы Рождества: 'время’ («Рождество пройдет быстро», «Праздник мимолетный» - наиболее частая ассоциация), 'цвет/свет' («Галчонок черный - символ Рождественской ночи», «Наступит темнота», «Рождественский вечер», «Галчонок выделяется на белом фоне зимы, как выделяется Рождество»), ‘детство’ («Галчонок, потому что мир вновь празднует рождение младенца», «Галчонок связан с детством», «Детское поведение, любопытство»). Есть и смысл 'чудо', а также его мотивация: «Галчонок выжил в морозы, а это Божественное чудо». Заметно, однако, что во всех ответах глагол глянет особой семантической роли не играет, его будто и нет.

Интерпретация смысла тропа осложняется метонимическими отношениями основного субъекта и вспомогательного, что выводит его за пределы прямой метаморфозы, позволяя включить в тот подтип, который В.В. Виноградов определил как «изысканное сравнение». Это определение не очень подходит для термина, но аналитическое сочетание «сложная (или осложненная) метаморфоза» подходит вполне. Такая метаморфоза рождается не из свернутого суждения метафорического тождества типа уже упомянутого Жизнь моя - кинематограф. В основе ее лежит широко понимаемая метонимия, включающая как отношения пространственно-временной смежности (в данном случае смежности праздника Рождество и неперелетной птицы галки, объединенных хронотопом зимы), так и количественные отношения «часть-целое» (глаз заменен именем целого - «галчонком»). Эти отношения лежат на поверхности, но что значит глянуть галчонком?

Возможна и такая интерпретация: Рождество глянет не просто чернотой ночи, а своей звездой, светящейся в этой черноте, тем более что тема Рождественской звезды была для Пастернака значимой. Почему выбрана уменьшительная форма галчонок, ясно без комментария. Что же касается взгляда галчонка, то из всех птиц семейства врановых только у галок белые глаза, резко контрастирующие с их оперением. Предложенная интерпретация достаточно непростого для понимания фрагмента одного из ранних стихов Б. Пастернака опирается на знание действительности, говоря словами В. Шкловского, — на «примерку слова к нашим знаниям». И «метафорическая редукция считается завершенной, когда читатель находит третье виртуальное понятие, выполняющее роль шарнира между двумя другими. У каждого читателя может быть свое собственное семантическое представление. 
Главное - найти самый короткий путь, соединяющий два объекта» [Дюбуа 1986: 196]. При этом остается бесспорным афоризм Аристотеля, согласно которому «в поэзии предпочтительней невозможное, но убедительное, возможному, но неубедительному» [Аристотель 1978: 161].

2.3. Хотя единой типологии метафор в филологии не существует, отличие метафоры от метонимии в дополнительной аргументации не нуждается. Однако есть особые случаи создания таких речевых конструкций, которые на поверхности языка выступают как метафоры, тогда как в основе их создания лежит метонимия. Данные «Русского ассоциативного словаря», созданного под руководством Ю.Н. Караулова, убеждают в том, что наглядные ассоциативные образы абстрактного имени возникают метонимически, например: СВОБОДА - лето, берег, cmепь, мама, баррикады, Нью-Йорк. Об этом же свидетельствуют и многочисленные словоупотребления в художественных текстах: Упали бы соблазнов сети с несчастной совести моей; И каждый вечер падаю, сражен усталости последним почелуем (В. Ходасевич); Грязный, гремучий, в постель Падает город с дороги; Tbl спал, постлав постель на сплетне (Б. Пастернак).

Р. Якобсон определил две логические возможности речепорождения: «Речевое событие может развиваться по двум смысловым линиям: одна тема может переходить в другую либо по подобию (сходству), либо по смежности» [Якобсон 1990: 126]. Предложенное Р. Якобсоном в одной из ранних работ понимание метафоры как «параллелизма, эллиптически сведенного к точке» [Якобсон 1987: 299], считается «не вполне прозрачной с точки зрения классической риторики трактовкой» [Цвигун 2007: 69]. Между тем в якобсоновской трактовке заложен глубокий смысл, но соотносится его трактовка лишь с одним типом метафоры, выделенным в рамках современной лингвистической концепции, которая была разработана Н. Д. Арутюновой и В.Н. Телия - с метафорой предикатной, или когнитивной, связанной с вербализацией невидимого мира и создающей его признаковую лексику (твердая воля, горькая истина, потерять терпение, найти причину).

3.1. В контексте известного текста Смерть не страшна, с ней в бою мы встречались не раз, вот и теперь надо мною она кружится когнитивная метафора она (смерть) кружится возникла в результате компрессии (или широко понимаемого эллипсиса) целого предложения, отражающего восприятие наблюдателем конкретной ситуации: вороньё кружится над полем боя. Но восприятие этой ситуация прочно стоит на лингвокультурном стереотипе, в котором вороньё - символ смерти. Кружение воронья в ситуации «поле боя» - ее знаковая, символически осмысляемая часть, позволяющая имени смерть принять в качестве вторичного предиката глагол кружиться в его переносном значении с имплицитным вспомогательным субъектом вороньё. Механизм возникновения метафоры в этом и многих других подобных случаях - синекдоха, трактуемая традиционно как разновидность метонимии и связываемая с обозначением ситуации (в данном контексте - это возможная смерть на поле) по ее неотъемлемой пространственной части (вороньё), связанной, в свою очередь, с целостной ситуацией причинно-следственными отношениями (где смерть, там вороньё). Налицо параллелизм актантов ситуации, 
«эллиптически сведенный к точке», если эллипсис понимать достаточно широко как компрессию текста, обусловленную особенностями поэтического мышления.

3.2. При сравнении переводов хорошо известного «66 сонета» Шекспира на русский язык метонимическая метафора обнаруживается в разных, но совпадающих синтагмах: Мне видеть невтерпеж Достоинство, что просит подаянья (пер. С. Маршака), Устал я жить и умереть хочу, Достоинство в отрепье видя рваном (пер. А. Финкеля). Хотя в оригинале во второй строке представлено имя лица a beggar - 'нищий, бедняк, попрошайка' (As, to behold desert a beggar born), на фоне олицетворенных абстракций, из которых соткан сонет, и оно в этих переводах перифрастически представлено как «бедное, нищее достоинство», но может быть передано и дословно: Тоска смотреть, как мается бедняк (пер. Б. Пастернака).

В таких контекстах, как Одиночество ест со сковородки (Т. Толстая), работает тот же самый механизм метафоризации метонимии. Н. Д. Арутюнова отмечает, однако, что «переход признакового значения в идентифицирующее неблагоприятен для метафоры» и что такая метафора «обычно имеет искусственный характер» [Арутюнова 1999: 360]. Следует, однако, отметить, что этот механизм срабатывает всегда, когда целое называется по его части, но когда частью является не предмет одежды, как в привычном примере Старый тулуп крякнул, а гипостазированный параметр (например, мудрость), обрастающий своими вторичными предикатами, как, например, в контексте Когда обиженная мудрость пронзает мир колючим взглядом, остерегаться ее надо, где именем мудрость названа нарисованная сова со злым взглядом.

В первой строке стихотворения О. Мандельштама (а оно же и название) Еще обиду тянет с блюдия Невыспавшееся дитя, А мне уж не на кого дуться, Ия один на всех путях наблюдаются те же самые отношения, хотя метонимическая метафора обозначает не субъект действия, а его объект. Замечание Н. Д. Арутюновой о том, что «метонимия выполняет в предложении идентифицирующую функцию и ориентирована на позицию субъекта и других актантов» [Арутюнова 1990: 31], такого рода примерами только подтверждается. Можно сказать, что метонимическая метафора представляет собой особый прием обозначения референта, точнее, его ракурса, создающий достаточно высокое герменевтическое напряжение.

В статье под названием «Гримасы прогресса» речь идет о том, как жители Японии оказались жертвами мусора: Япония доросла до диктатуры мусора. Что дальme? («Огонёк». 2018, № 1). Останавливает внимание не столько словосочетание (1) диктатура мусора, сколько (2) гримасы прогресса. В (1) обыденной субстанции под названием мусор через когнитивную (и одновременно генитивную) метафору приписывается предикат беспредельной власти, поскольку слово диктатура означает такую форму власти, которая опирается не на закон, а на силу, из чего следует коннотативная сема 'власть' собирательного имени мусор. В (2) абстрактная сущность прогресс (движение вперед, улучшение) осмысляется через ее проекцию на искаженное эмоцией лицо человека (в полном соответствии со значением имени гримаса), что порождает оксюморон за счет столкновения противоположных 
сем — 'хороший (улучшение)' имени прогресс и 'плохой’ имени гримаса, поскольку гримасы лица выражают, как правило, отрицательные эмоции. При этом и в (1), и в (2) представлена персонификация абстрактных феноменов за счет их соединения с антропоцентрическими предикатами, но когнитивная метафора гримасы прогресса осложнена метонимическими отношениями участников ситуации, где мусор - каузатор «неправильности» прогресса.

3.3. В.П. Григорьев, исследуя «метафоры-сравнения» особое внимание обращает на соединение в генитивной структуре имен конкретного и абстрактного (телега жизни, белая птица спасения), считая эти случаи «более сложными», «интерпретация которых как СрМтф далеко не очевидна» [Григорьев 1979: 200]. Но и эти «способы словопреобразования» подпадают под когнитивную метафору, что позволяет углубить ее типологию. Представляется лингвистически обоснованным исследование взаимодействия не только метафоры и сравнения, но также метонимии и метафоры в поэтическом тексте с его «теснотой и единством стихового ряда» (Ю. Тынянов), в создании которых большую роль играет эллипсис. А метафора как универсальный способ создания новых смыслов из столкновения старых, всем известных слов, остается одним из приоритетных объектов неологии, особенно если метафора рождается из метонимии (ее частного случая - синекдохи), усложняющей мотивационную базу метафоры.

Под термин «неология» в [Дюбуа 1986: 112] подводится любое новое употребление слова (по Аристотелю - это «переносные» имена) в текстах тех жанров, которые не только допускают интерпретативное видение мира, но ориентированы на него. Актуальность изучения новых употреблений «старых» слов В.В. Виноградов видел в том, что такой лингвистический предмет позволяет «уловить потенциальные тенденции смыслового развития слов», для чего «целесообразно исследовать и способы их индивидуально-творческого применения и преобразования» [Виноградов 1977: 167-168]. Самым важным для неологии предметом является, очевидно, стык простых, обыденных слов в поэтическом тексте, на котором возникает множество смыслов, в основном нетривиальных, открывающих новое знание или представление о мире. Не так важно при этом, получат ли эти смыслы санкцию общеупотребительного языка.

\section{Литература}

Аристотель и античная литература. М.: Наука, 1978. 231 с.

Арутюнова Н.Д. Язык и мир человека. М.: ЯРК, 1999. 896 с.

Барт Р. Основы семиологии // Структурализм: «за» и «против». М.: Прогресс, 1975. C. $114-163$.

Виноградов В. В. Избранные труды. Лексикология и лексикография. М.: Наука, $1977.310 \mathrm{c}$.

Григорьев В. П. Поэтика слова. М.: Наука, 1979. 344 с.

Дюбуа Ж. и др. Общая риторика. М.: Прогресс, 1986. 392 с.

Левин Ю. И. Избранные труды. М.: ЯРК, 1998. 824 с. 
Мукаржовский Ян. Исследования по эстетике и теории искусства. М.: Искусство, 1994. 606 с.

Уилрайт Ф. Метафора и реальность // Теория метафоры. М.: Прогресс, 1990. C. 82-109.

Цвигун Т. В. Метонимия как «нулевая степень письма» Романа Якобсона // Вестник БФУ им. И. Канта. Серия: Филология, Педагогика, Психология. Калининград. 2007, № 6. С. 69-73.

Шкловский $B$. Тетива. О несходстве сходного // Собрание сочинений. В 3 томах. Т. 3. М.: Худлит, 1974. С. 465-786.

Шnет Г. Г. Работа по философии // Логос. 1991. № 2. С. 215-233.

Якобсон Р. Новейшая русская поэзия // Работы по поэтике. М.: Прогресс, 1987. C. 272-316.

Якобсон Р. Два аспекта языка и два типа афатических нарушений // Теория метафоры. М.: Прогресс, 1990. С. 110-132.

\section{O. Cherneiko}

Lomonosov Moscow State University

(Russia,Moscow)

avollis@mail.ru

\section{METONYMY TO METAPHOR: THE PARADOX OF COGNITIVE METAPHORS}

The article covers several theoretical issues related to epidigmatics (specifically, the typology of the derived meaning of the word) and the typology of cognitive metaphors. The emphasis is on the use of existing lexical units, which Aristotle called names with «transferred» meaning and which are one of the most important subjects of neology. It seems also very important to concentrate on the hermeneutic aspect of transferred metaphorical uses of the word in a poetical text, the goal of which is to discover their motivational base. The cognitive metaphor, complicated by the underlying metonymy, is a trope which is most difficult to understand; it is structured as a metaphor-riddle. On the material of the poetic texts the interpretation of «transfers» which are not obvious for understanding is offered. Special attention is paid to abstract substantives, for which cognitive metaphor is a natural form of existence in speech associated with verbalization of the invisible world and creating its attributive vocabulary. R. Jakobson's interpretation of metaphor as «parallelism elliptically reduced to a point», refers not to any metaphor, but only to the cognitive metaphor complicated with metonymy — to the «metonymic metaphor». The article proposes an understanding of the mechanism of metaphorization of metonymy: the whole is called by its part, but the part is not a piece of clothing, but a hypostatized parameter overgrown with its secondary predicates, which is demonstrated by examples from literary texts and by the translations of Shakespeare's Sonnet 66. 
Key words: indirect derived meaning, riddle, metamorphosis, metaphor, metonymy, metonymic metaphor, associative sense.

\section{References}

Aristotel' $i$ antichnaya literatura [Aristotle and ancient literature]. Moscow, Nauka Publ., 1978. 231 p.

Arutyunova N.D. Yazyk i mir cheloveka [Language and the world of man]. Moscow, Yazyki Russkoi Kul'tury Publ., 1999. 896 p.

Bart R. [Fundamentals of semiology]. Strukturalizm: «za» $i$ «protiv» [Structuralism: «for» and «against»]. Moscow, Progress Publ., 1975, pp. 114-163. (In Russ.).

Dubois J. et al. Obshchaya ritorika [General rhetoric]. Moscow, Progress Publ., 1986. $392 \mathrm{p}$.

Grigor'ev V.P. Poetika slova [Poetics of the word]. Moscow, Nauka Publ., 1979. $344 \mathrm{p}$.

Jakobson R. [The latest Russian poetry]. Raboty po poetike [Works on poetics.]. Moscow, Progress Publ., 1987, pp. 272-316.

Jakobson R. [Two aspects of language and two types of aphatic disorders]. Teoriya metafory [Theory of metaphor]. Moscow, Progress Publ., 1990, pp. 110-132. (In Russ.).

Levin Yu. I. Izbrannye trudy [Selected works]. Moscow, Yazyki Russkoi Kul'tury, 1998. 824 p.

Mukařovský Jan. Issledovaniya po estetike i teorii iskusstva [Research on aesthetics and art theory]. Moscow, Iskusstvo Publ., 1994. 606 p.

Shklovskii V. [Bowstring. About dissimilarity of similar]. Sobranie sochinenii [Collected works]. In 3 volumes. Vol. 3. Moscow, Khudozhestvennaya Literatura, 1974, pp. 465-786. (In Russ.).

Shpet G. G. [Work on philosophy]. Logos, 1991, no. 2, pp. 213-233. (In Russ.).

Tsvigun T. V. [Metonymy as «zero degree of writing» by Roman Jakobson]. Vestnik BFU im. I. Kanta. Ser. Filologiya, Pedagogika, Psikhologiya. Kaliningrad, 2007, no. 6, pp. 69-73. (In Russ.).

Vinogradov V. V. Izbrannye trudy. Leksikologiya i leksikografiya [Selected works. Lexicology and lexicography]. Moscow, Nauka Publ., 1977. 310 p.

Wheelright P. [Metaphor and reality]. Teoriya metafory [Theory of metaphor]. Moscow, Progress Publ., 1990, pp. 82-109. (In Russ.). 